\title{
Behavioural and biochemical effects of an ICV injection of streptozotocin in old Lewis rats
}

Citation for published version (APA):

Blokland, A., \& Jolles, J. (1994). Behavioural and biochemical effects of an ICV injection of streptozotocin in old Lewis rats. Pharmacology, Biochemistry and Behavior, 47(4), 833-837.

https://doi.org/10.1016/0091-3057(94)90284-4

Document status and date:

Published: 01/01/1994

DOI:

10.1016/0091-3057(94)90284-4

Document Version:

Publisher's PDF, also known as Version of record

\section{Please check the document version of this publication:}

- A submitted manuscript is the version of the article upon submission and before peer-review. There can be important differences between the submitted version and the official published version of record.

People interested in the research are advised to contact the author for the final version of the publication, or visit the DOI to the publisher's website.

- The final author version and the galley proof are versions of the publication after peer review.

- The final published version features the final layout of the paper including the volume, issue and page numbers.

Link to publication

\footnotetext{
General rights rights.

- You may freely distribute the URL identifying the publication in the public portal. please follow below link for the End User Agreement:

www.umlib.nl/taverne-license

Take down policy

If you believe that this document breaches copyright please contact us at:

repository@maastrichtuniversity.nl

providing details and we will investigate your claim.
}

Copyright and moral rights for the publications made accessible in the public portal are retained by the authors and/or other copyright owners and it is a condition of accessing publications that users recognise and abide by the legal requirements associated with these

- Users may download and print one copy of any publication from the public portal for the purpose of private study or research.

- You may not further distribute the material or use it for any profit-making activity or commercial gain

If the publication is distributed under the terms of Article $25 \mathrm{fa}$ of the Dutch Copyright Act, indicated by the "Taverne" license above, 


\title{
Behavioral and Biochemical Effects of an ICV Injection of Streptozotocin in Old Lewis Rats
}

\author{
ARJAN BLOKLAND ${ }^{1}$ AND JELLEMER JOLLES \\ University of Limburg, Department of Neuropsychology and Psychobiology, \\ P.O. Box 616, 6200 MD Maastricht, The Netherlands
}

Received 8 February 1993

\begin{abstract}
BLOKLAND, A. AND J. JOLLES. Behavioral and biochemical effects of an KCV injection of streptozotocin in old Lewis rats. PHARMACOL BIOCHEM BEHAW 47(4) 833-837, 1994.--Intracerebroventricularly (ICV) injected streptozotocin (STREP) decreases central glucose metabolism and energy metabolism, which has allso been observed in patients with dementia. In the present study we examined the behavioral (open-field behavior and two-way active avoidance learning) and biochemical (hippocampal ChAT activity) effects of STREP treatment in old Lewis rats. The results suggest that hippocampal function was affected by STREP. STREP-treated rats acquired the two-way active avoidance task faster than the control rats, which indicates that STREP treatment does not lead to a general learning deficit. Hippocampal ChAT activity was decreased in STREP-treated rats. The present results suggest also that susceptibility to STREP may not be related to age in Lewis rats.
\end{abstract}

Animal model Streptozotocin Glucose metabolism Cholline acetyltransferase activity Hippocampus Alzheimer"s disease Learning

DURING the last decade, much effort has been made to develop animal models of cognitive aging and dementia [e.g., $(7,26)]$. Valid animal models of dementia and of the agerelated decline in cognitive functions could lead to a better understanding of the mechanisms underlying the cognitive deficits and may eventually lead to clinical treatments.

There are several studies that indicate that a reduced glucose metabolism in the brain is related to the cognitive dysfunctions in animals as well in humans [e.g., $(8,12,28)]$. Thus, a lowered use of glucose in the brain could underlie the decrease in cognitive functions in aging and dementia [see (12)]. This hypothesis could be tested in animals in which the use of brain glucose is lowered experimentally.

Streptozotocin (STREP) has been used to induce experimental diabetes melitus in rats when administered intraperitoneally (20). STREP acts via different mechanisms, such as inhibition of the insulin synthesis in pancreas islet cells (5), decrease in autophosphorylation of the insulin receptor kinase (17), and suppression of an insulin responsive glucose transporter (13). When applied intracerebroventricularly ICV, STREP may affect the insulin synthesis and/or the insulin receptor function and, consequently, impair the transport of glucose, provided that insulin acts in the same manner in the brain as it acts in nonnervous tissue (18).

Different studies support the hypothesis that an ICV injection of STREP reduces the use of glucose in the brain. It has been reported that, compared to control rats, the arteriovenous difference for glucose increases, whereas the arteriovenous difference for lactate increases in STREP-treated rats (22). The increase in lactate/glucose ratio may reflect a shift in carbohydrate metabolism in favor of the glycolytic breakdown. Furthermore, it has been found that the brain glucose level is increased in STREP-treated rats, suggesting that the uptake of glucose in the brain is decreased (21). In the same study it was found that also the ATP/ADP ratio was decreased. Blood glucose levels and lacate levels were not affected after ICV STREP treatment, indicating that the peripheral energy metabolism is unaltered (21). Because these effects

\footnotetext{
${ }^{1}$ Requests for reprints should be addressed to Dr. A. Blokland at his present address: Institute for Neurobiology, Department of Gerontopharmacology, Troponwerke, Berliner Strasse 156, D-51063 Cologne, Germany.
} 
are found 3 weeks after a single injection with STREP, this treatment may provide an animal model of prolonged central metabolic neuronal stress (21).

STREP treatment has also been found to affect the concentrations of different neurotransmitters in the brain which is most likely caused by the STREP-induced decrease in energy metabolism $(9,15)$. Hippocampal choline acetyltransferase activity has been found to be decreased after STREP treatment $(3,15)$. In a study in which the effects of STREP on brain monoaminergic neurotransmitter concentrations were evaluated in more detail, it was found that noradrenaline, dopamine, and serotonin were differentially decreased in distinct brain areas (9). It was speculated that the selective vulnerability of neurons might be related to properties (density of insulin receptors) and the brain area of the neurons. Interestingly, a comparable effect on different neurotransmitter sysitems in the brain have been observed in dementia of the Alzheimer type $[\mathrm{e} . \mathrm{g}, \ldots(14,16)]$.

The behavioral effects of an ICV injection of STREP are, however, less well studied. It has been reported that rats injected ICV with STREP show an increase in spontaneous locomotor activity and are impaired in the passive avolidance task (19). We have demonstrated that performance in a spatial Morris water escape task is affected in middle-aged rats treated ICV with STREP (3). Moreover, this impaired spatial discrimination performance was found to be related to a decrease in hippocampal ChAT activity "In contrast to middleaged rats, spatial discrimination performance and hippocampal ChAT activity was not affected in young STREP-treated rats (3).

However, we found a substantial variation in behavioral and biochemical parameters in middle-aged STREP-treated rats, which was greater than in control rats (3). It could be suggested that the effect of STREP treatment is dependent on the susceptibility of individual rats. Because STREP treatment had virtually no effect in young rats, it could be argued that the factor age could mediate the susceptibility of rats to $1 \mathrm{CV}$ STREP treatment.

In the present study we examined the behavioral and biochemical effects of ICV STREP treatment in old Lewis rats. We assumed that all old rats would be susceptible to STREP treatment and that, therefore, the variation in the parameters would not be as substantial as that observed in the middleaged rats in our previous study (3). Another aim of this study was to evaluate whether the behavioral effects of STREP treatment could be related to hippocampal dysfunction. Therefore, we tested the old rats in tasks that are sensitive to hippocampal function (open-field behavior and two-way active awoidance learning). We did not test the old rats in the Morris spatial navigation task because we have found that old Lewis rats do not show place learning in this task (unpublished data) and, thus, hippocampal function cannot be examined in old rats with this task. We also measured hippocampal ChAT activity and assessed whether there was a correlation between ChAT activity and the behavioral data.

\section{METHOD}

\section{Animals}

Nineteen 24-month-old male Lewis rats were used. All rats were housed individually in standard Makrolon cages on sawdust bedding in an air-conditioned room (about $20^{\circ} \mathrm{C}$ ). They were kept under a 12:12 hour light:dark cycle (lights on from 0900 to $2100 \mathrm{~h})$.

\section{Surgery}

Two weeks before behavioral testing the rats were assigned at random to either the control group (CON: $n=9$ ) or the STREP group ( $n=10$ ). The rats were anesthetized with pentobarbital $(60 \mathrm{mg} / \mathrm{kg}$ IP) and placed in a stereotaxic frame. The STREP group was given a bilateral ICV injection of STREP (1.5 mg/kg body weight dissolved in $4 \mu \mathrm{l}$ saline, $2 \mu \mathrm{l}$ per injection site). The stereotaxic coordinates were: -0.8 $\mathrm{mm}$ anterior, $1.55 \mathrm{~mm}$ lateral, and $-3.8 \mathrm{~mm}$ from the bregma (25). The control group underwent the same surgical procedures but saline was injected ICV instead of STREP. One $\mathrm{CON}$ rat died during the operation.

\section{Behavioral Procedures}

Open field. Open-field behavior was assessed in a square box (100 $\times 100 \mathrm{~cm})$ subdivided by black lines into 36 equal squares. Two red fluorescent strip lights provided very dim illumination (about 2 lux) on the floor of the apparatus. Immediately after a rat was placed in the center of the open field, its movements were scored. The total number of line crossings, the time spent in the corner squares, rearing, and grooming were recorded manually with an MS-DOS computer. Testing was carried out on four consecutive days in 5-min sessions.

Shock sensitivity. Before the rats were subjected to twoway active avoldance training we first assessed the shock sensitivity of the rats. The rats were placed in a box $(40 \times 25 \times$ 40), which was different from the box used in the shuttle box task. The floor was connected to a shock scrambler. The intensity of the shock was increased step wise, starting at 0.05 $\mathrm{mA}$, with increments of $0.05 \mathrm{~mA}$. The shock intensity at which a rat first flinched was scored as the first shock sensitivity level. After the shock intensity was again increased by 0.05 $\mathrm{mA}$, the shock intensity was decreased in a similar manner as it was increased. The second shock sensitivity level was scored when a rat failed to flinch when a shock was given.

Shutte box. Acquisition of two-way active avoidance learning was assessed in an automated shuttle box. The apparatus consisted of two equal compartments $(21 \times 13.5 \times 20$ $\mathrm{cm}$ ), separated by a barrier (height $3 \mathrm{~cm}$ ). The floor consisted of a metal grid connected to a shock scrambler. The animals were trained in one session of 50 trials. The session was preceded by an adaptation period of $5 \mathrm{~min}$. A trial started with the presentation of an auditory stimulus as a warning signal. The signal was terminated when a rat crossed the barrier within $8 \mathrm{~s}$; otherwise, a foot shock $(0.30 \mathrm{~mA})$ was given. The foot shock was terminated when the rat escaped to the other compartment or when 10 s had elapsed. The intertrial interwal waried randomly between 35 and $60 \mathrm{~s}$.

Hippocampal ChAT activity. The same procedures were followed as described in our previous study (3), using the method of Fonnum (10).

\section{Data Analysis}

Except for shuttle box performance, differences between groups were analyzed by using $t$-statistics. Correlations between parameters were calculated within experimental groups by using Pearson's correlation coefficient.

Open field. The data of the open-field test were aggregated over days to enhance reliability (24). The mean time spent in the corner squares was transformed logarithmically $\left(\operatorname{Ln}\left[\left(t_{1}+t_{2}+t_{3}+t_{4}\right)\right)_{4}\right]$; subscripts refer to day 1 through 4 of testing) to remove inhomogeneity. 
Shock sensitivity. The average of the two shock sensitivity levels of individual rats was calculated and taken as the sensitivity to shock.

Shuttle box. In the SB task the overall level of performance (mean number of awoidance responses per block of 10 trials) was assessed. The data of the shuttle box task were analyzed in a two-factor (treatment by trial block) analysis of variance with repeated measures over trial blocks. Group differences in overall performance (general mean) and in the shape of the learning curves were analyzed in a one-factor analysis of wariance on orthogonal trend components calculated over the successive trial blocks (27).

\section{RESULTS}

\section{Body Weight}

The body weights of CON and STREP rats did not differ before, $t(16)=1.59$, NS, or after, $t(16)=0.66$, NS, behavioral testing.

\section{Open Field}

The rats of the CON and STREP groups displayed similar behavioral activity in the open field, as expressed by the same number of line crossings, $t(16)=0.33$, NS; see Fig. 1A). The time spent in the different areas was, however, different for the CON and STREP groups (see Fig. 1B). The rats of the STREP group spent more time in the center and wall squares, $t(16)=3.71, p<0.01$, and $t(16)=4.04, p<0.01$, respectively, whereas the rats of the CON group spent more time in the corner squares, $t(16)=5.02, p<0.01$. The frequency of grooming behavior was similar in the CON and the STREP-treated rats [mean(SEM), CON: $1.72(0.21)$ STREP: $1.75(0.22) ; t(16)=0.10, \mathrm{NS}]$. However, the frequency of rearing was markedly reduced in the STREP-treated rats as compared to the CON rats [mean(SEM), CON: 6.19(0.88) STREP: $1.2(0.36) ; t(16)=5.65, p<0.01]$.

\section{Shock Sensitivity}

The CON and the STREP-treated rats did not differ in their sensitivity to shock [mean(SEM), CON: $0.13(0.01)$ STREP: $0.11(0.01) ; t(16)=0.53$, NS]

\section{Shuttle Box}

During the adaptation period that preceded acquisition training, the STREP-treated rats crossed the barrier as often
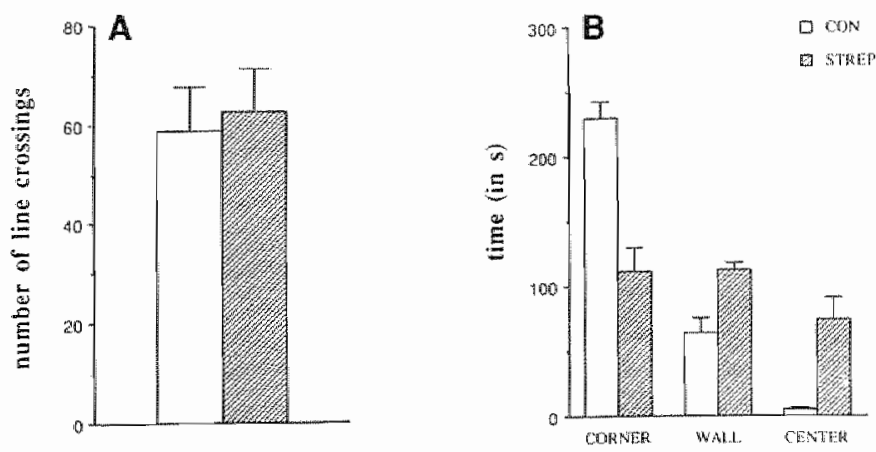

FIG. 1. Total number of line crossings (A) and total time spent in the different areas (B) of the open field (aggregated data of four 5-min sessions per day) for old CON and STREP-treated Lewis rats.

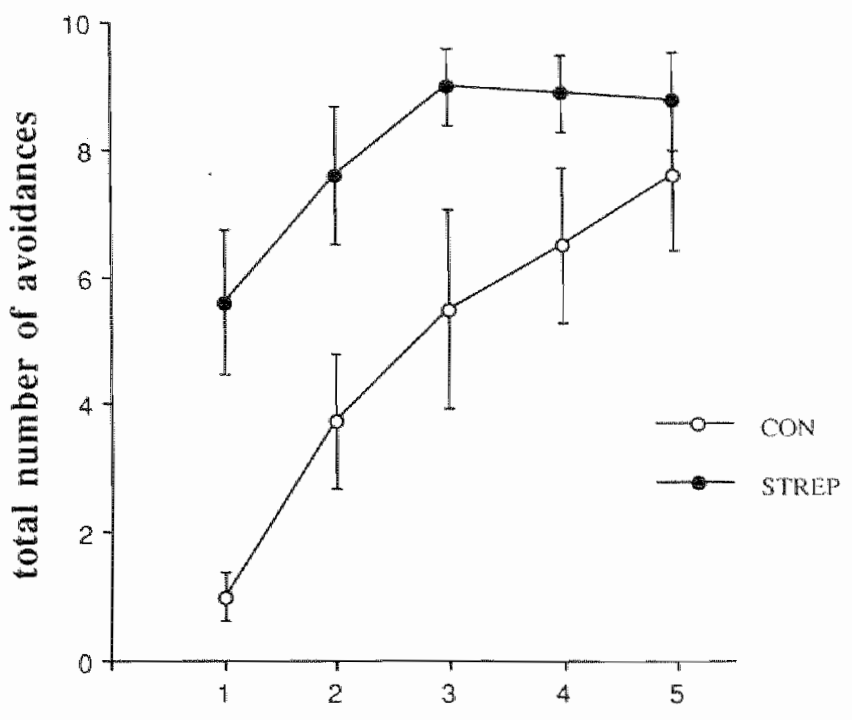

blocks of 10 trials

FIG. 2. Total number of avoidance responses per block of 10 trials in a two-way active avoidance shutule box task for old CON and STREP-treated Lewis rats.

as the CON rats [mean(SEM), CON: 5.13(0.91) STREP: $4.1(0.94) ; t(16)=0.77$, NS]. The number of avoidance responses of both the CON and STREP-treated rats increased. in the course of training, $F(4,64)=17.55, p<0.01$. This increase was mainly characterized by a linear trend, $F(1,16)$ $=32.84, p<0.01$ (see Fig.2), and was similar for the CON and the STREP-treated rats [group by trial block: $F(4,64)$ $=1.99$, NS]. During training, however, the STREP-treated rats made more avoidance responses than the CON rats [general mean: $F(1,16)=7.58, p<0.05 \mathrm{~J}$. Evaluation of group differences on indlividual trial blocks showed that the STREP. treated rats made more avoidance responses during the first three trial blocks than the CON rats, ts $>2.26, p<0.05$, but that the number of avoidance responses was equal for both groups during the last two trial blocks, $t s>1.87$, NS.

\section{Hippocampal ChAT Activity}

Hippocampal ChAT activity was decreased in STREPtreated rats [mean(SEM) nmol $/ \mathrm{h} / \mathrm{mg}$ protein, CON: 100.54(2.21) STREP: $76.54(9.01) ; t(16)=2.32, p<0.05]$.

\section{Correlations}

Hippocampal ChAT activity correlated only incidentally with behavior. Hippocampal ChAT activity was positively correlated with the mean number of avoidance responses in the shuttle box task in the CON rats $(r=0.72, p<0.05)$. Grooming behavior and ChAT activity were found to be correlated in the STREP-treated rats $(r=-0.66, p<0.05)$.

\section{DISCUSSION}

The STREP and the CON rats displayed similar levels of activity in the open field, whereas we had assumed that STREP treatment affected hippocampal function. Because hippocampal lesions increase open-field activity [e.g., $(6,23]$, we had expected that the number of line crossings would be 
higher in the STREP-treated rats. It could be argued that no effect of STREP treatment was found because of ceiling effects. Old rats show marked motor impairments (11) that affect their physical ability to increase activity. In addition, it should be mentioned that the activity measures in the open field cannot be interpreted in the same way in old rats as in young rats [see (4)]. The frequency of grooming was also found to be similar in the STREP-treated and the CON rats. It has been reported that hippocampal lesions decrease selfgrooming in rats (6). The lack of effect of STREP treatment, however, was probably due to the low frequency of grooming in both the CON and the STREP-treated rats (i.e., floor effect). It could, however, also be argued that the effects of STREP treatment are less severe than hippocampal lesions or ablations and that, therefore, no effect of STREP treatment could be found on the measures line crossings and grooming. Therefore, these data are not conclusive with respect to hippocampal dysfunction after STREP treatment.

The number of rearings was substantially lower in the STREP-treated rats than in the CON rats, which suggests that STREP treatment reduces exploratory activity (23). Furthermore, the CON rats showed a clear preference for the corner squares in the open field, whereas the STREP-treated rats showed no preference for any of the three areas. These findings could be explained in terms of hippocampal dysfunction: a decrease in exploration (less rearing) and a lack of knowledge of fear (more time in center squares) (23).

The STREP-treated rats acquired the two-way active avoidance task faster than the CON rats. This improved performance of the STREP-treated rats can be explained in terms of an impaired hippocampal function. Hippocampectomized rats cannot apply place strategies in avoidance learning but can only use cue strategies [see (2)]. If a rat uses a place strategy in the two-way active avoidance task, it may experience a conflict because it is shocked in both parts of the apparatus. This conflict situation retards avoidance learning. If a rat uses a cue strategy instead of the maladaptive place strategy, it will not experience this conflict situation which, as a consequence, facilitates acquisition of the task. The finding that the STREP-treated rats acquired the twomway active avoidance task faster than the CON rats demonstrates that STREP treatment does not cause a general learning impair- ment but may cause a deficit related to specific regions of the brain (e.g., hippocampus).

Hippocampal ChAT activity was found to be decreased in STREP-treated rats, as has also been found in other studies $(3,15)$. However, there was a substantial variation in ChAT activity in the STREP group (range: $\min 8.71$ to $\max 100.51$ $\mathrm{nmol} / \mathrm{h} / \mathrm{mg}$ protein). We had assumed that all rats would be equally susceptible to STREP treatment and that, therefore, the variation in the STREP group would be small. Apparently, the susceptibility to STREP treatment in Lewis rats is not dependent on age. It would be interesting to examine which factor(s) determines the susceptibility to STREP treatment in Lewis rats. The variation in the behavioral measures, however, was comparable for the STREP and the CON groups. This observation could be explained by the lack of relation between hippocampal ChAT activity and behavior (see below). It could be argued that the behavioral parameters are not dependent on hippocampal function (more specific, ChAT activity) to a great extent, and that other neural substrates, which are not affected by STREP treatment, may be involved in these behaviors.

Only two behavioral measures were correlated with hippocampal ChAT activity. These correlations should, however, be interpreted with caution because the variation in one of the measures was small (ChAT activity in the CON group and grooming in the STREP group), which may bias the correlation coefficient. Although there was a decrease in hippocampal ChAT activity and improvement in shuttle box performance, these two measures were not correlated in the STREP group. It could be argued that performance in the shuttle box is also dependent on other factors (e.g., reactivity to the shock) and that this is why no correlation was found between the two measures.

In conclusion, the present study showed that ICV-injected STREP, as a method to decrease central glucose utilization, affects behaviors that are reported to be related to hippocampal function and decreases hippocampal ChAT activity. The better performance of the rats of the STREP group in the shuttle box task indicates that STREP treatment does not result in a general decline in learning and memory performance. It is not likely that the susceptibility of Lewis rats to STREP treatement is related to age.

\section{REFERENCES}

1. Adelstein, T. B.; Kesner, R. P.; Strassberg, D. S. Spatial recognition and spatial order memory in patients with dementia of the Alzheimer's type. Neuropsychologica $30: 59-67 ; 1992$.

2. Black, A. H.; Nadel, L.; O'Keefe, J. Hippocampal function in avoidance learning. Psychol. Bull. 84:1107-1129; 1977.

3. Blokland, A.; Jolles, J. Spatial learning deficit and reduced hippocampal ChAT activity after an ICV injection of streptozotocin. Pharmacol. Biochem. Behav. 44:491-494; 1993.

4. Blokland, A.; Raaijmakers, W.; van der Staay, F. J.; Jolles, J. Differential effect of of acetyl-1-carnitine on open-field behavior in young and old rats. Physiol. Behaw. 47;783-785; 1990.

5. Bolaffi, J. L.; Nagamatsu, S.; Harris, J.; Grodsky, G. M. Protection by thymidine, an inhibitor of polyadenosine diphosphate ribosylation, of streptozotocin inhibition of insulin secretion. Endocrinology 120:2117-2122; 1987.

6. Camnon, R. L.; Paul, D. J.; Baisden, R. H.; Woodruff, M. L. Alterations in selfgrooming in the rat as a consequence of hippocampal damage. Psychobiology 20:205-218; 1992.

7. Dawson, G. R.; Heyes, C. M.; Iversen, S. D. Pharmacological mechanisms and animal models of cognition. Behav. Pharmacol. 3:285-297; 1992 .
8. Deleon, M. J.; Harris, S..H.; George, A. E.; Reisberg, B.; Christman, D. R ; Kricheff, I. 1.; Wolf, A. P. Computed tomography and positron emission transaxial tomography evaluation of normal aging and Alzheimer's disease. J. Cereb. Blood Flow Metab. 3:391-394; 1983 .

9. Ding, A.; Nitsch, R.; Hoyer, S. Changes in brain monoaminergic neurotransmitter concentrations in rat after intracerebroventricular injection of streptozotocin. J. Cereb. Blood Flow Metab. 12: 103-109; 1992.

10. Fonnum, F. A rapid radiochemical method for the determination of choline acetylltransferase. J. Neurochem. 24:407-409; 1975.

11. Gage, F. H.; Dunnett, S. B.; Björklund, A. Spatial learning and motor deficits in aged rats. Neurobiol. Aging 5:43-48; 1984 .

12. Gage, F. H.; Kelly, P. A. T.; Björklund, A. Regional changes in brain glucose metabolism reflect cognitive impairments in aged rats. J. Neurosci. 4:2856-2865; 1984.

13. Garvey, W. T.; Hueckstead, T. P.; Birnbaum, M. J. Pretranslational suppression of an insulin-responsive glucose transporter in rats with diabetes mellitus. Science $245: 60-63 ; 1989$.

14. Gottfries, C. G.; Adolfsson, R.; Acquilonius, S. M.; Carlsson, A.; Eckernäs, S. A.; Nordberg, A.; Oreland, L.; Svennerholm, 
L.; Wiberg, A.; Winblad, B. Biochemical changes in dementia disorders of the Alzheimer type (AD/SDAT). Neurobiol. Aging $4: 261-271 ; 1983$.

15. Hellweg, R.; Nitsch, R.; Hock, C.; Jaksch, M.; Hoyer, S. Nerve growth factor and choline acetyltransferase activity levels in the rat brain following experimental impairment of cerebral glucose and energy metabolism. J. Neurosci. Res. 31:479-486; 1992 .

16. Herregodts, P.; Bruyland, M.; DeKeyser, J.; Solheid, C.; Michotte, $Y_{\text {.; }}$ Ebinger, G. Monoaminergic neurotransmitter in Alz heimer's disease. J. Neurol. Sci. 92:101-116; 1989.

17. Kadowaki, T.; Kasuga, M.; Akanuma, Y.; Ezaki, O.; Takaku, F. Decreased autophosphorylation of the insulin receptor-kinase in streptozotocin-diabetic rats. J. Biol. Chem. 259:14208-14216; 1984.

18. Kahn, C. R. The molecular mechanism of insulin. Annu. Rev. Med. $36: 429-451 ; 1985$.

19. Mayer, G.; Nitsch, R.; Hoyer, S. Effects of changes in peripheral and cerebral glucose metabolism on locomotor activity, Jearning and memory in adult male rats. Brain Res. 532:95-100; 1990.

20. Mordes, J. P.; Rossini, R. A. Animal models of diabetes. Am. J. Med. $70: 353-360 ; 1981$.
21. Nitsch, R.; Hoyer, S. Local action of the diabetogenic drug, streptozotocin, on glucose and energy metabolism in rat brain cortex. Neurosci. Lett. 128:199-202; 1991.

22. Nitsch, R.; Mayer, G.; Hoyer, S. The intracerebroventriculary streptozotocintreated rat: Impairment of cerebral glucose metabolism resembles the alterations of carbohydrate metabolism of the brain in Alzheimer's disease. J. Neural Transm. 1:109-110; 1989.

23. O'Keefe, J. Nadel, L. The hippocampus as a cognitive map. Oxford: Clarendon Press; 1978:240-264.

24. Ossenkop, K. P.; Mazmanian, D. S. The principle of aggregation in psychobiological correlation research: An example from the open-field test. Anim. Learn. Biehav. 13:339-344; 1985.

25. Paxinos, G.; Watson, C. The rat brain in stereotaxic coordinates, 2nd ed. Sidney: Academic Press; 1986.

26. Shiosaka, S. Attempts to make models for Alzheimers disease. Neurosci. Res. 13:237-255:1992.

27. Winer, B. J. Statistical principles in experimental design. New York: McGraw Hill Book Company; 1971.

28. Wree, A.; Kaever, C.; Birgel, B.; Schleicher, A.; Horwath, E.; Zilles, $K$. Local cerebral glucose utilization in the rat brain of old, learning impaired rats. Histochemistry 95:591-603; 1991. 